\title{
Depressive and adjustment disorders - some questions about the differential diagnosis: case studies
}

This article was published in the following Dove Press journal:

Neuropsychiatric Disease and Treatment

26 July 2010

Number of times this article has been viewed

\section{A Presicci' \\ P Lecce' \\ PVentura' \\ F Margari ${ }^{2}$ \\ S Tafuri ${ }^{3}$ \\ L Margari'}

'Child Neuropsychiatric Unit, Department of Neurologic and Psychiatric Science, Aldo Moro University of Bari, Bari, Italy; ${ }^{2}$ Psychiatric Unit, Department of Neurologic and Psychiatric Science, Aldo Moro University of Bari, Bari, Italy; ${ }^{3}$ Hygiene Section, Department of Biomedical Science and Human Oncology, Aldo Moro University of Bari, Bari, Italy
Correspondence: Lucia Margari Child Neuropsychiatric Unit, Department of Neurologic and Psychiatric Science, University of Bari, Azienda Ospedaliera Policlinico, Piazza Giulio Cesare, I I, 70 I 24 Bari, Italy

Tel +39-080-547-8520

Fax +39-080-547-8532

Email l.margari@neurol.uniba.it
Background: Diagnosis and treatment of mood disorders in youth are still problematic because in this age the clinical presentation is atypical, and the diagnostic tools and the therapies are the same as that used for the adults. Mood disorders are categorically divided into unipolar disorders (major depressive disorder and dysthymic disorder) and bipolar disorder in Diagnostic and Statistical Manual of Mental Disorders (Fourth Edition, Text Revision), but mood symptoms are also comprised in the diagnostic criteria of the adjustment disorder (AD), which occur in many different psychiatric disorders, and may also be found in some physical conditions. The differential diagnosis is not much addressed in the midst of clinical investigation and so remains the major problem in the clinical practice.

Aims: The associations between some variables and the depressive disorder and AD were analyzed to make considerations about differential diagnosis.

Patients and methods: We reported a retrospective study of 60 patients affected by depressive disorder and AD. The analysis has evaluated the association between some variables and the single diagnostic categories. We have considered 10 variables, of which 6 are specific to the disorders, and 4 have been considered related problems.

Results: The statistical analysis showed significant results for the associations of 3 variables (prevalent symptoms, treatment, and family history) with the single diagnostic categories.

Conclusion: The discriminate analysis resulted in statistically significant differences between patients with depressive disorders and those with $\mathrm{AD}$ on 3 variables, of which 2 are specific to the disorders, and 1 is included in the related problems. The other variables were weakly associated with the single diagnostic categories without any statistically significant differences. The 3 variables that were associated with the single diagnostic categories support the distinct construct validity of the 2 diagnostic categories, but, to date, it is difficult to establish if these variables can be considered diagnostic predictors. On the other hand, the other variables did not support the distinct construct validity of the 2 diagnostic categories, which suggest an overlapping and dimensional concept. The spectrum approach could unify categorical classification that is essential with a dimensional view. Combination of dimensional and categorical principles for classifying mood disorders may help to reduce the problems of underdiagnosis and undertreatment.

Keywords: depressive disorder, bipolar disorder, spectrum

\section{Introduction}

Despite the great attention directed toward the diagnosis and treatment of depression in children and adolescents in the past years, underdiagnosis and undertreatment remain major problems in mood disorders of childhood because the clinical presentation is atypical, and the diagnostic tools and the therapies are the same as that used for the adults. ${ }^{1}$ The World Health Organization predicts that depression will be the 
world's leading cause of disability by 2020, in the whole age range. ${ }^{2}$ Mood disorders in childhood and adolescence cause significant cognitive, academic, social, and emotional impairment and increase the risk of other negative health outcomes, so precocious diagnosis and treatment are needed.

Mood disorders are categorically divided into unipolar disorders (major depressive disorder [MDD] and dysthymic disorder [DD]) and bipolar disorder (BD) in the Diagnostic and Statistical Manual of Mental Disorders (Fourth Edition, Text Revision) (DSM-IV-TR), ${ }^{3}$ but mood symptoms are also comprised in the diagnostic criteria of the adjustment disorder (AD), which occur in many different psychiatric disorders, and may also be found in some physical conditions.

In childhood and adolescence, MDD and DD are characterized by irritable mood, associated with several depressive symptoms and feelings; however, expression of symptom varies with developmental stage, and some children and adolescents may have difficulty identifying and describing internal mood states. ${ }^{4-21}$ The prevalence of MDD ranges from $1.8 \%$ to $2.5 \%$ for children and from $2.9 \%$ to $4.7 \%$ for adolescents and the prevalence of DD ranges from $0.6 \%$ to $4.6 \%$ for children and from $1.6 \%$ to $8 \%$ for adolescents. ${ }^{2,22-24} \mathrm{BD}$ is not a single disorder but a category of mood disorders and is defined as the presence of 1 or more episodes of abnormally elevated mood, which is clinically referred to as mania. Individuals who experience manic episodes also commonly experience depressive episodes or symptoms or mixed episodes that present with features of both mania and depression. ${ }^{25-29}$ There is evidence for an increased risk of developing BD in young people with depression, so precocious depression seems to be a possible precursor of BD. ${ }^{11,25}$ The prevalence of juvenile $\mathrm{BD}$ ranges from $0.2 \%$ to $0.4 \%$ for prepubertal populations and is about $1 \%$ for adolescents, usually with a depressive episode as the first episode in $40 \% .^{11,25-30}$

$\mathrm{AD}$ is characterized by emotional and behavioral symptoms, which occur in close temporal relationship to stressful events, and is time-limited. ${ }^{31-38}$ The distress is more than what would be expected, given the nature of the stressors, and causes significant impairment in social or academic functioning. On the basis of predominant symptoms, the categories of DSM-IV-TR include AD with depressed mood, anxiety, mixed anxiety and depressed mood, disturbance of conduct, and mixed disturbance of emotions and conduct. The prevalence of $\mathrm{AD}$ ranges from $2 \%$ to $8 \%$ for children and from $12.5 \%$ to $34 \%$ for adolescents. ${ }^{3,39-41}$

Mood symptoms occur in many different psychiatric disorders, such as anxiety, disruptive behavioral, eating, personality, schizoaffective disorders, and learning disabilities. Moreover, some physical conditions (in particular, endocrine and neurologic diseases) may also express them with mood symptoms.

So the differential diagnosis is the major problem in clinical practice. Although there is an extensive body of literature regarding depression in adults, to date, there have been a relatively few previous population-based studies that examine the problems of differential diagnosis in mood disorders. The distinction between unipolar disorders and $\mathrm{BD}$ is probably the best established of the subdivisions between the mood disorders, which have been supported by several different lines of evidence. However, mania is rare in children. Moreover, some symptoms of depression could be considered predictor of BD. ${ }^{30,42}$ So, the differential diagnosis between these 2 disorders is still difficult in childhood. Moreover, at no age it is clear where the line should be drawn between clinical depressive disorder and feelings of sadness, which is based on adversity, such as in AD.

We have retrospectively studied a childhood population affected by mood disorder and AD. The aim of this study is to consider differential diagnosis between these diagnostic categories. In order to do this, several groups of variables, some of these specific to the disorders and others being related problems, were analyzed.

\section{Patients and methods Patients}

Data are collected from a case sheets study of a cohort of inpatient sample of 60 children and adolescents (28 male, 32 female), aged between 5 and 17 years (mean age 11.75; $\mathrm{SD}=3.1$ ), who were referred to the Child Neuropsychiatric Unit, University of Bari, from January 2004 to December 2008. According to DSM-IV-TR criteria, all patients were categorized into 2 groups: depressive disorders (MDD and DD) and AD.

\section{Methods}

\section{Procedures}

During the first neuropsychiatric visit, a clinical interview with patients and their parents provided a developmental history exploring premorbid development, onset of symptoms, symptoms, stressors, social context, and dysfunction. Then, all patients were tested through an individualized assessment, comprising psychodiagnostic and clinical and instrumental procedures.

For all patients, the psychodiagnostic assessment included the following: self-interviews, observer semistructured interviews, rating scales, administered individually to the 
children and adolescents and to their parents, some of these exploring general psychopathology and other specific for mood disorders (schedule for affective disorders, schizophrenia for school-age children - present and lifetime version, child behavior checklist, children depression rating scale, children depression inventory, screening for child's anxiety-related disorders); projective tests (spontaneous drawing, familial test, children's apperception test, and thematic apperception test). In the cases suspected for mental retardation and/or learning disabilities, intelligence (Wechsler Preschool and Primary Scale of Intelligence, Wechsler Intelligence Scale for Children-III) and academic evaluations were performed to assess comorbidity.

The clinical and instrumental assessment comprised physical and neurological examinations, general laboratory investigations, and on the basis of individual needs, electroencephalogram and magnetic resonance imaging.

\section{Data analysis}

The analysis involved 10 variables of the disorders, collected during the enrolment evaluation: 6 considered specific to the disorders (characteristics of the sample at first consultation, reasons of first consultations, duration of symptoms, severity, treatment, and prevalent symptoms); 4 considered related problems of the disorders (family history, sender, life stressors, comorbidity). In order to detect possible specific associations between the variables and the single disorder and to make considerations about differential diagnosis, the statistical analysis was performed using $2 \times 2$ contingency tables. Chi square $\left(\chi^{2}\right)$ (with the Fisher exact test when indicated), odds ratio (OR), and 95\% confidence interval $(\mathrm{CI})$ were estimated. The $P<0.05$ value has been considered significant. The data elaboration was performed by the software Epi-Info 6.00 (public domain software: CDC, Atlanta, Georgia, USA; WHO, Geneva, Switzerland).

\section{Results}

\section{Specific variables of the disorders}

\section{Characteristic of the sample}

In accordance with the DSM-IV-TR criteria,${ }^{3}$ the patients received the following diagnosis (Table 1):

- Depressive disorder: 33 patients (55\%), of whom 25 (42\%) were affected by MDD (14 female, 11 male, aged from 5 to 17 years) and 8 (13\%) by DD (4 male, 4 female, aged from 8 to 15 years).

- AD: 27 patients (45\%) (15 female, 12 male, aged from 6 to 17 years).
The mean age at the first consultation was 12.9 years $(\mathrm{SD}=3)$ for $\mathrm{MDD}, 10.9$ years $(\mathrm{SD}=2)$ for $\mathrm{DD}$, and 10.9 years $(\mathrm{SD}=3.1)$ for $\mathrm{AD}$ groups.

\section{Reasons of first consultation}

We have grouped those patients in 5 categories (Table 1):

1. The somatic complaints included mainly headache, abdominal pain, changes in sleep pattern, loss of appetite, and loss of energy (32\% MDD, 37.5\% DD, and 30\% AD).

2. The school problems included poor performances in school, disengagement from academic results, reduced ability to concentrate, school refusal, frequent school absences, and change of class with difficult adjustment. School problems were more frequent in patients with $\mathrm{AD}$ (41\%) than in patients with DD $(37.5 \%)$ or MDD $(8 \%$; $\chi^{2}=4.97, P=0.02$ ).

3. The behavioral problems included psychomotor agitation, aggressiveness, and disruptive behavior (12\% MDD, $12.5 \% \mathrm{DD}, 22 \% \mathrm{AD})$.

Table I Specific variables of the disorders

\begin{tabular}{|c|c|c|c|}
\hline & $\begin{array}{l}\text { MDD } \\
N=25 \\
(42 \%)\end{array}$ & $\begin{array}{l}\text { DD } \\
N=8 \\
(13 \%)\end{array}$ & $\begin{array}{l}A D \\
N=27 \\
(45 \%)\end{array}$ \\
\hline \multicolumn{4}{|c|}{ Characteristic of the sample at first consultation } \\
\hline Male & II (44\%) & $4(50 \%)$ & $12(44 \%)$ \\
\hline Female & $14(56 \%)$ & $4(50 \%)$ & $15(66 \%)$ \\
\hline Age $(y)$, mean $\pm S D$ & $12.9,3$ & $10.9,2$ & $10.9,3$ \\
\hline Range (y) & $5-17$ & $8-15$ & $6-17$ \\
\hline \multicolumn{4}{|l|}{ Age distribution (y) } \\
\hline Range 3-5 & $\mathrm{I}(4 \%)$ & - & - \\
\hline Range 6-II & $6(24 \%)$ & $6(75 \%)$ & $16(59 \%)$ \\
\hline Range $12-18$ & $18(72 \%)$ & $2(25 \%)$ & II (4I\%) \\
\hline \multicolumn{4}{|c|}{ Reasons of first consultation } \\
\hline Somatic complaints & $8(32 \%)$ & $3(37.5 \%)$ & $8(30 \%)$ \\
\hline School problems & $2(8 \%)$ & $3(37.5 \%)$ & II (4I\%) \\
\hline Behavioral problems & $3(12 \%)$ & I (I2.5\%) & $6(22 \%)$ \\
\hline Affective symptoms & $7(28 \%)$ & I (I2.5\%) & $2(7 \%)$ \\
\hline Suicidal behaviors & $5(20 \%)$ & - & - \\
\hline \multicolumn{4}{|l|}{ Duration of symptoms } \\
\hline Wks & $5(20 \%)$ & - & $2(7.5 \%)$ \\
\hline Mo & $7(28 \%)$ & - & $7(26 \%)$ \\
\hline Iy & I (4\%) & $2(25 \%)$ & $3(11 \%)$ \\
\hline $2-8 y$ & $12(48 \%)$ & $6(75 \%)$ & $15(55.5 \%)$ \\
\hline \multicolumn{4}{|l|}{ Severity } \\
\hline Mild & $3(12 \%)$ & I (I2.5\%) & $8(30 \%)$ \\
\hline Moderate & $9(36 \%)$ & $4(50 \%)$ & $12(44 \%)$ \\
\hline Severe & $13(52 \%)$ & $3(37.5 \%)$ & 7 (26\%) \\
\hline \multicolumn{4}{|l|}{ Treatment } \\
\hline Only psychotherapy & $6(24 \%)$ & $8(100 \%)$ & 20 (74\%) \\
\hline $\begin{array}{l}\text { Pharmacotherapy and } \\
\text { psychotherapy }\end{array}$ & $19(76 \%)$ & 0 & $4(15 \%)$ \\
\hline Social services & - & - & $3(11 \%)$ \\
\hline
\end{tabular}

Abbreviations: MDD, major depressive disorder; DD, dysthymic disorder; $A D$, adjustment disorder, $S D$, standard deviation. 
4. The affective symptoms included depressed or irritable mood, anxiety, loss of enjoyment, low self-esteem, and feelings of worthlessness, inappropriate guilt, or hopelessness. Affective symptoms were more frequent in patients with MDD (28\%) than in patients with DD $(12.5 \%)$ or $\operatorname{AD}\left(7 \% ; \chi^{2}=3.96, P<0.05\right.$, Fisher exact $)$.

5. The suicidal behaviors included expressing suicidal thoughts or intent to commit suicide and having a suicidal plan, such as taking pills or hanging oneself at a specific place and time, and self injury or attempted suicide (20\% MDD).

\section{Duration of symptoms}

Clinical interview revealed that $48 \%$ of MDD, $75 \%$ of DD, and $55.5 \%$ of AD groups had symptoms many years before the diagnosis (Table 1).

\section{Severity}

The severity was assessed on the basis of symptoms and impairment of global functioning, using Children's Global Assessment Scale. In the all groups, the moderate to severe forms were prevalent [moderate: 36\% MDD, 50\% DD, and $44 \% \mathrm{AD}$; severe: $52 \% \mathrm{MDD}, 37.5 \% \mathrm{DD}$, and $26 \% \mathrm{AD}$ (Table 1)].

\section{Treatment}

Twenty-four percent of MDD, 100\% of DD, and 74\% of AD patients underwent psychological therapy $\left(\chi^{2}=7.06\right.$, $P=0.0007)$. The psychological therapy was associated with the diagnosis of $\mathrm{AD}(\mathrm{OR}=3.39 ; 95 \% \mathrm{CI}, 1.03-11.5$; $\chi^{2}=5.17, P=0.02$ ) (Table 1).

Seventy-six percent of MDD and $15 \%$ of AD patients underwent combination therapy (psychological and psychopharmacological therapy); $11 \%$ of AD patients were admitted to the social services.

The combination therapy was associated with the diagnosis of MDD $\left(\mathrm{OR}=22.96 ; 95 \% \mathrm{CI}, 4.86-122.97 ; \chi^{2}=24.25\right.$, $P<0.0001)$.

\section{Prevalent symptoms}

The reported and observed prevalent symptoms, at the first observation, were different in all groups and they varied with respect to the reasons of the first consultation. These prevalent symptoms were depressed or irritable mood, loss of enjoyment, eating disturbances, sleep disturbances, psychomotor abnormalities, fatigue or loss of energy, low self-esteem, feelings of worthlessness, inappropriate guilt, or hopelessness, reduced ability to concentrate, recurrent thoughts of death or suicidal behaviors, mental over activity (flights of ideas and racing or crowded thoughts), vague physical complaints, psychotic symptoms, poor performances in school, disengagement from peer play, anxiety, and behavioral problems. The following symptoms were more frequent in the MDD groups than in other groups: eating disturbances $\left(\chi^{2}=4.00, P=0.04\right)$, psychomotor abnormalities $\left(\chi^{2}=5.19, P=0.02\right)$, fatigue or loss of energy $\left(\chi^{2}=4.76, P=0.04\right)$, and feelings of worthlessness, inappropriate guilt, or hopelessness $\left(\chi^{2}=5.68, P=0.02\right.$ ) (Table 2$)$.

The loss of enjoyment was more frequent $\left(\chi^{2}=7.33\right.$; $P=0.009)$ in the DD group than in other groups. The feelings of worthlessness, inappropriate guilt, or hopelessness were less frequent in the AD group than in other groups $\left(\chi^{2}=8.66\right.$; $P=0.002)$.

Statistical analysis showed that MDD was associated with vague physical complaints $(\mathrm{OR}=12.67 ; 95 \% \mathrm{CI}, 3.19-54.33$; $\left.\chi^{2}=18.62, P<0.0001\right)$, while AD was associated with poor performances in school $(\mathrm{OR}=6.73 ; 95 \% \mathrm{CI}, 1.62-30.34$; $\left.\chi^{2}=9.49, P=0.002\right)$ and behavioral problems $(\mathrm{OR}=13.47$; 95\% CI, 1.48-310.12; $\left.\chi^{2}=8.24, P=0.005\right)$.

\section{Variables of the related problems of the disorders}

\section{Family history}

We have considered the family history of generic neuropsychiatric illness and more specifically, mood dis-

Table 2 Prevalent symptoms of the disorders

\begin{tabular}{|c|c|c|c|}
\hline & $\begin{array}{l}\text { MDD } \\
N=25 \\
(42 \%)\end{array}$ & $\begin{array}{l}D D \\
N=8 \\
(13 \%)\end{array}$ & $\begin{array}{l}A D \\
N=27 \\
(45 \%)\end{array}$ \\
\hline Depressed/irritable mood & $17(68 \%)$ & 7 (28\%) & $16(59 \%)$ \\
\hline Loss of enjoyment & $6(24 \%)$ & $\mathrm{I}(12.5 \%)$ & $6(22 \%)$ \\
\hline Eating disturbances & II (44\%) & I (I2.5\%) & $6(22 \%)$ \\
\hline Sleep disturbances & 7 (28\%) & $5(62.5 \%)$ & $13(48 \%)$ \\
\hline Psychomotor abnormalities & $9(36 \%)$ & I (I2.5\%) & $3(11 \%)$ \\
\hline Fatigue or loss of energy & $5(20 \%)$ & - & I (4\%) \\
\hline Low self-esteem & $8(32 \%)$ & $4(50 \%)$ & $7(26 \%)$ \\
\hline $\begin{array}{l}\text { Feelings of worthlessness, } \\
\text { inappropriate guilt, } \\
\text { or hopelessness }\end{array}$ & 7 (28\%) & $2(25 \%)$ & - \\
\hline Reduced ability to concentrate & I (4\%) & $2(25 \%)$ & I (4\%) \\
\hline $\begin{array}{l}\text { Recurrent thoughts of death } \\
\text { or suicidal behaviors }\end{array}$ & $6(24 \%)$ & - & - \\
\hline $\begin{array}{l}\text { Mental over activity (flights of } \\
\text { ideas, racing/crowded thoughts) }\end{array}$ & $3(12 \%)$ & - & - \\
\hline Vague physical complaints & $19(76 \%)$ & $4(50 \%)$ & $3(11 \%)$ \\
\hline Psychotic symptoms & $2(8 \%)$ & - & - \\
\hline Poor performance in school & $4(16 \%)$ & - & $13(48 \%)$ \\
\hline Disengagement from peer play & $8(32 \%)$ & $3(37.5 \%)$ & $9(33 \%)$ \\
\hline Anxiety symptoms & $13(52 \%)$ & $3(37.5 \%)$ & $9(33 \%)$ \\
\hline Behavioral problems & - & I (I2.5\%) & $8(30 \%)$ \\
\hline
\end{tabular}

Abbreviations: MDD, major depressive disorder; DD, dysthymic disorder; $A D$, adjustment disorder. 
orders. Fifty-six percent of MDD, 37\% of DD, $18 \%$ of AD patients showed familiarity for mood disorders.

Familiarity for mood disorders was associated with the diagnosis of $\mathrm{MDD}\left(\mathrm{OR}=4.30 ; 95 \% \mathrm{CI}, 1.23-15.45 ; \chi^{2}=6.9\right.$, $P=0.008)$.

Familiarity for generic neuropsychiatric disorders was more frequent in patients with $\mathrm{AD}(55 \%)$ than in patients with MDD $(32 \%)$ and DD $\left(24 \% ; \chi^{2}=3.9, P=0.04\right)$.

\section{Sender}

We have considered the following senders who sent the patients to the child neuropsychiatrist: clinicians (48\% MDD, $50 \% \mathrm{DD}$, and $18 \% \mathrm{AD}$ ), families (20\% MDD, $37.5 \% \mathrm{DD}$, and $41 \% \mathrm{AD}$ ), teachers ( $12.5 \% \mathrm{DD}$ and $26 \% \mathrm{AD}$ ), first aid station (24\% MDD and 4\% AD), and social services and/or juvenile court ( $8 \% \mathrm{MDD}$ and $11 \% \mathrm{AD})$. The first aid station was more frequent in the MDD group than in other groups $\left(\chi^{2}=6.33\right.$; $P=0.01)$ and teachers were more frequent $\left(\chi^{2}=6.74 ; P=0.01\right)$ in the $\mathrm{AD}$ group, while clinicians were less frequent, than in other groups $\left(\chi^{2}=5.80 ; P=0.01\right)$ (Table 3$)$.

\section{Life stressors}

One or more stressful life events were found in $88 \%$ of MDD group, $87 \%$ of DD group, and $100 \%$ of AD group (Table 3).

We have grouped them in 6 categories: familial problems (such as divorce, dysfunctional family relationships, poor communication style, parental or relative's illness, and adoption), bereavement, bullying, abuse, illness, school problems (such as learning disabilities and leaving school). The familial problems were more frequent in the DD group than in other groups $\left(\chi^{2}=5.19 ; P=0.02\right)$.

\section{Comorbidity}

The comorbidities were found in $64 \%$ of MDD, $87.5 \%$ of $\mathrm{DD}$, and $70 \%$ of AD groups. The personality disorder was more frequent in the MDD group $\left(\chi^{2}=4.76 ; P=0.04\right)$, while learning disorders were more frequent in the $\mathrm{AD}$ group than in other groups $\left(\chi^{2}=3.94 ; P=0.04\right)$ (Table 3 ).

\section{Discussion}

Although there is an extensive body of literature regarding depression in adults, to date, there have been a relatively few previous population-based studies that examine the problems of the differential diagnosis of mood disorders in childhood. $32,33,36,37,43-46$

Although the criteria for all mood disorders are the same for children and adolescents as they are for adults, there
Table 3 Variables of the related problems of the disorders

\begin{tabular}{|c|c|c|c|}
\hline & $\begin{array}{l}\text { MDD } \\
N=25 \\
(42 \%)\end{array}$ & $\begin{array}{l}\text { DD } \\
N=8 \\
(13 \%)\end{array}$ & $\begin{array}{l}A D \\
N=27 \\
(45 \%)\end{array}$ \\
\hline \multicolumn{4}{|l|}{ Family history } \\
\hline $\begin{array}{l}\text { Familiarity for mood } \\
\text { disorders }\end{array}$ & 14 (56\%) & $3(37 \%)$ & $5(18 \%)$ \\
\hline $\begin{array}{l}\text { Familiarity for } \\
\text { neuropsychiatric illness }\end{array}$ & $8(32 \%)$ & $2(25 \%)$ & 15 (55\%) \\
\hline \multicolumn{4}{|l|}{ Sender } \\
\hline Clinicians & $12(48 \%)$ & $4(50 \%)$ & $5(18 \%)$ \\
\hline Families & $5(20 \%)$ & $3(37.5 \%)$ & II (4I\%) \\
\hline Teachers & - & I (12.5\%) & $7(26 \%)$ \\
\hline First aid station & $6(24 \%)$ & - & I (4\%) \\
\hline $\begin{array}{l}\text { Social services and/or } \\
\text { juvenile court }\end{array}$ & $2(8 \%)$ & - & $3(11 \%)$ \\
\hline \multicolumn{4}{|l|}{ Life stressors } \\
\hline Presence of life stressors & $22(88 \%)$ & $7(87 \%)$ & $27(100 \%)$ \\
\hline Familial problems & $9(36 \%)$ & $7(87 \%)$ & $14(52 \%)$ \\
\hline Bereavement & $6(24 \%)$ & - & $6(22 \%)$ \\
\hline Bullying & $2(8 \%)$ & - & - \\
\hline Abuse & $2(8 \%)$ & - & - \\
\hline Illness & - & - & $4(15 \%)$ \\
\hline School problems & I (4\%) & - & $3(11 \%)$ \\
\hline \multicolumn{4}{|l|}{ Comorbidity } \\
\hline Anxiety disorder & $4(16 \%)$ & - & - \\
\hline Personality disorder & $5(20 \%)$ & I (I2.5\%) & - \\
\hline Eating disorder & $3(12 \%)$ & - & I (4\%) \\
\hline ADHD & - & I (I2.5\%) & - \\
\hline Somatoform disorder & - & I (I2.5\%) & - \\
\hline Conversion disorder & - & - & I (4\%) \\
\hline Learning disorder & - & $4(50 \%)$ & $9(33 \%)$ \\
\hline Headaches & $3(12 \%)$ & I (I2.5\%) & $3(11 \%)$ \\
\hline Mental retardation & $4(16 \%)$ & $2(25 \%)$ & $4(15 \%)$ \\
\hline Tic disorder & - & - & I (4\%) \\
\hline No. of patients & $16(64 \%)$ & 7 (87.5\%) & $19(70 \%)$ \\
\hline
\end{tabular}

Abbreviations: MDD, major depressive disorder; DD, dysthymic disorder; $A D$, adjustment disorder; ADHD, attention deficit hyperactivity disorder.

are unique developmental challenges and considerations in diagnosing and treating disorders in youth. ${ }^{4-17,19,20,28}$

Although there is evidence that distinguishes unipolar disorder and $\mathrm{BD}$, indeed very few studies have reported on the problems related to the distinction between depressive disorder and $\mathrm{AD}$ and on the role of predictors for these 2 pathologies. Some studies have found differences between patients with $\mathrm{AD}$ and those with other mood disorders, which include severity of symptoms, psychosocial adaptation, and number and intensity of stressors. ${ }^{32,3436,38}$

In our sample, the depressive disorder and $\mathrm{AD}$ are fairly distributed. Although the statistical analysis was performed in a small group of patients, it is possible to make some considerations about the differential diagnosis.

The discriminate analysis revealed statistically significant differences between patients with MDD and DD and 
those with $\mathrm{AD}$ on 3 variables, of which 2 are specific to the disorders (prevalent symptoms and treatment) and 1 is included in the related problems (family history).

Although the majority of the prevalent symptoms were common among the 2 diagnostic categories, the unique symptoms that were more specific for MDD were the vague physical complaints $(P<0.0001)$, while that for AD were the poor performances in school $(P=0.002)$ and behavioral problems $(P=0.005)$. These findings are in accordance with the literature. For the depressive disorders, some symptoms (more the affective) are atypical, subtle, and not visible by the family, and are present in children who have limited ability to communicate emotions and thoughts, with consequent tendency toward somatization; moreover, depressive symptoms vary on the basis of the age and of the cognitive and social levels. ${ }^{4-13,19,28,47}$ Indeed, children express the emotional problems due to the stress as externalized symptoms (such as poor performances in school and behavioral problems) as in AD. ${ }^{32,40,43,48}$ The prevalent symptoms observed in our patients, such as vague physical complaints, poor performances in school, disengagement from peer play, anxiety symptoms, and behavioral problems, are not included in the diagnostic criteria of DSM-IV, confirming the literature data on the atypical presentation and the difficulties in diagnosing mood disorders in childhood. ${ }^{4-9,36,37,49-51}$

The second variable that was statistically significantly associated with the disorders was the treatment resulting from the psychological therapy specific for the AD group $(P=0.02)$ and the combination therapy for the MDD group $(P=0.0001)$; however, the psychological therapy emerged more frequently without statistical significance in the DD group $(P=0.0007)$.

With regard to the role of the family history, in our sample, $56 \%$ of MDD patients showed familiarity for mood disorders $(P=0.008)$, whereas $55 \%$ of AD patients showed familiarity for generic neuropsychiatric disorders $(P=0.04)$. Our findings confirm the literature data by supporting the principal role of the genetic factors in depressive disorders and of the environmental factors in AD. ${ }^{4,51-56}$ The role of the genetic factors in $\mathrm{AD}$ is still unclear. ${ }^{35,36,44}$

Seven variables, of which 4 are specific to the disorders and 3 are included in the related problems, are weakly associated with the single diagnostic categories, without statistically significant differences. These variables are characteristics of sample, duration of symptoms, reasons of first consultations, severity, sender, life stressors, and comorbidity.

With regard to the characteristics of the samples, considering the range of the age at the first observation, it seems that the depressive disorders affect older people more than patients with AD. Although the statistical analysis did not show significant results, some questions emerged. We have hypothesized that the MDD and DD have been recognized later for the atypical presentation. However, in our cases, we have been unable to estimate the exact age at which the symptoms began. The clinical interview revealed that the disorders really appeared early with respect to the time of diagnosis (many years before in $48 \%$ of MDD, $75 \%$ of DD, and $55.5 \%$ of AD groups). Only few parents present a child for evaluation after a 2-week period, as defined in DSM-IV-TR. Moreover, the onset of depression is often gradual, and only by looking previous months and sometimes years, a parent or even the child or adolescent can state that there has been a change in functioning. Perhaps, the ADs are recognized early compared with depressive disorders, which are always recognized later, because these disorders onset with externalized symptoms and also because, during a life stressor (such as bereavement and school problems), major attention has been directed toward the child. So, the precocious diagnosis remains a major problem in both the disorders.

Considering the reasons of first consultation, the affective symptoms were more frequent in the MDD group $(P<0.05$ Fisher exact), while poor performances in school were more frequent in the $\mathrm{AD}$ group $(P=0.02)$. Even though the results are not statistically significant, they overlap with the variables prevalent symptoms and sender for the AD group.

The symptoms were severe in all groups because all of our patients were hospitalized. With regard to the treatment, some $\mathrm{AD}$ patients received medication because of the severity of their symptoms.

We have hypothesized that the severity of depression has brought the patients to the first aid station, which resulted the prevalent sender $(P=0.01)$. Instead, the externalized symptoms of $\mathrm{AD}$ are perhaps perceived more troubling by the teachers, who were the prevalent senders $(P=0.01)$.

Although the familial problems were more frequent in DD patients $(P=0.02)$, none of the life stressors was associated with the disorders with a statistical significance. All evidence pointed to strong familial and school effects and to other weak life stressors for both the groups, supporting the strict relation to the context. To date, it is difficult to distinguish if the life stressors antedate or complicate the outcome of the disorder. Considering the high genetic role for the depressive disorders, the life stressors seem to manifest a depressive vulnerability. ${ }^{57}$ For the AD, in accordance with the literature data, it is difficult to establish if the patients showed a major vulnerability to stress or if an excess of life stressors determined negative effects in all the subjects; moreover, even though children 
show more resistance to stress, the effects of the life stressors are more severe if psychiatric familiarity exists. ${ }^{32,35,58,59}$

With regard to comorbidity, pure disorders were rare in our sample. Although the associations between the single comorbidity and the diagnostic groups did not show statistically significant results, personality disorders were more frequent in MDD group $(P=0.04)$, and learning disorders were more frequent in the $\mathrm{AD}$ group $(P=0.04)$. Complications in diagnosis and treatment and in differential diagnosis can arise from high rates of comorbidity by "masking" its presence. ${ }^{32,60}$ Even in a situation where the mood disorder precedes the comorbidity, the differences in diagnostic approach required by both disorders should be considered.

Finally, there is evidence for an increased risk of developing BD in young people with depression. In fact, in $40 \%$ of children or adolescents with $\mathrm{BD}$, the illness begins with a major depressive episode, and the switch rates to mania in adults were significantly lower $(3.9 \%)$ than in children (31.7\%). ${ }^{25,61-63}$ Moreover, considering that the recognition of the $\mathrm{BD}$ was delayed by as much as 8-10 years and that unipolar depression remains an uncertain diagnosis lifelong, it is impossible to establish how many of the our depressive patients will become bipolar. This question did not help us to distinguish these 2 disorders.

Also the construct validity of AD has not been established, and there are relatively few studies on the disorders. ${ }^{32,34-36,38}$

The 3 variables that were statistically associated with the single diagnostic categories support the distinct construct validity of the single diagnostic categories, but, to date, it is difficult to establish if these variables can be considered diagnostic predictors. On the other hand, the other variables did not support the distinct construct validity of the diagnostic categories, which suggests an overlapping and dimensional concept.

The diagnostic problems are certainly related to the features of the developmental psychopathology, which studies developmental transformations and reorganization occurring over the time. In fact, a particular stress or underlying mechanism may result in different behavioral difficulties at different times in the developmental process and in different contexts, and the developmental transformations and reorganizations occurring over the time modify the expression of the disorders or lead to new symptoms and difficulties.

Moreover, the difficulties in diagnosis and treatment of mood disorders in youth are also related to the interpretation of the interaction between genetic and environmental factors (personal vulnerability and life stressors) because specific types of stressful events and individual patterns of stress response appear to be differentially related to the onset of psychiatric syndromes. ${ }^{64-68}$

To alleviate the problems of underdiagnosis and undertreatment of mood disorders, it is possible to introduce the concept of spectrum in clinical practice. The term "spectrum" was first used in psychiatry by Kety et al ${ }^{69}$ for the schizophrenia spectrum and then proposed for the treatment of affective disorders during the past decade. Recently, the division between bipolar and unipolar has also been questioned by the continuity or spectrum concept of mood disorders, which includes the overlapping and dimensional disorders ranging from $\mathrm{BD}$ to MDD. ${ }^{63,70,71}$ Moreover, in the clinical practice, the distinction between depressive disorder and $\mathrm{AD}$ are unclear.

The actual diagnostic systems are limited for diagnosing childhood psychiatric disorders, especially in preschool age. In mood disorders of childhood and adolescence, an excessive focusing on the symptoms is limitative, and defining the syndrome of depression in terms of number of symptoms only may give rise to error. From a clinical practice point of view, findings of our study suggest not only a systematic assessment of the depressive symptoms but also the affective and individual significances of the symptoms in the context of the development. Health care professionals should also consider the age of onset, reasons of first consultation, duration of symptoms, severity, familiarity, sender, life stressors, comorbidity, and predictor factors of BD.

The spectrum approach could unify categorical classification that is essential with a dimensional view. Combination of dimensional and categorical principles for classifying mood disorders may help to reduce the problems of underdiagnosis and undertreatment. The development of a validated mood spectrum concept can provide a more differentiated research and treatment model for mood disorders and may help to reduce the underrecognition of bipolarity.

The small size of the sample represents a limitation, but it is possible that with a greater number of cases some of our data, actually resulted "border" at the statistical analysis, may become more specific.

It may take longer than expected to develop bettervalidated diagnostic criteria. The diffusion of guidelines and the forthcoming International Classification of Diseases, Eleventh Revision (ICD-11) and Diagnostic and Statistical Manual of Mental Disorders (Fifth Edition) (DSM-V) may give us new definitions.

\section{Disclosure}

The authors report no conflicts of interest in this work. 


\section{References}

1. National Institute of Mental Health (NIMH). Depression in children and adolescents (Fact sheet for physicians). NIH publication No. 00-4744 (2001). 2000. Available from: http://www.nimh.nih.gov/publicat/ depchildresfact

2. World Health Organization (WHO). Priority medicines for Europe and the world. 2004. Available from: http://www.who.int/mental_health/ management/depression/definition/en/, http://www.who.int/mip2001/ files/1956/Depression.pdf

3. American Psychiatric Association (APA). Diagnostic and Statistical Manual for Mental Disorders. Fourth Edition. Text Revision. (DSM-IV-TR). American Psychiatric Association, Washington, DC; 2000.

4. Kovacs M, Akiskal S, Gatsonis C, Parrone PL. Childhood-onset dysthymic disorder. Clinical features and prospective naturalistic outcome. Arch Gen Psychiatry. 1994;51:365-374.

5. Kovacs M. Presentation and course of major depressive disorder during childhood and later years of the life span. J Am Acad Child Adolesc Psychiatry. 1996;35:705-715.

6. Kovacs M, Paulaskas S, Gatsonis C, Richards C. Depressive disorders in childhood. III. A longitudinal study of comorbidity with and risk for conduct disorders. J Affect Disord. 1988;15:205-217.

7. Kovacs M, Devlin B, Pollock M, Richards C, Mukerji P. A controlled family history study of childhood-onset depressive disorder. Arch Gen Psychiatry. 1997;54:613-623.

8. Birmaher B, Ryan ND, Williamson DE, et al. Childhood and adolescent depression: a review of the past 10 years, Part I. JAm Acad Child Adolesc Psychiatry. 1996;35:1427-1439.

9. Birmaher B, Ryan ND, Williamson DE, Brent DA, Kaufman J. Childhood and adolescent depression: a review of the past 10 years, Part II. J Am Acad Child Adolesc Psychiatry. 1996;35:1575-1583.

10. Birmaher B, Brent DA, Benson RS. Summary of the practice parameters for the assessment and treatment of children and adolescents with depressive disorder. American Academy of Child and Adolescent Psychiatry. J Am Acad Child Adolesc Psychiatry. 1998;37: 1234-1238.

11. Birmaher B, Arbelaez C, Brent D. Course and outcome of child and adolescent major depressive disorder. Child Adolesc Psychiatr Clin NAm. 2002;11(3):619-637.

12. Birmaher B, Williamson DE, Dahl RE, et al. Clinical presentation and course of depression in youth: does onset in childhood differ from onset in adolescence? J Am Acad Child Adolesc Psychiatry. 2004; 43(1):63-70.

13. American Academy of Child and Adolescent Psychiatry (AACAP). Practice parameters for the assessment and treatment of children and adolescent with depressive disorders. J Am Acad Child Adolesc Psychiatry. 1998;37(10):63-83.

14. Park RJ, Goodyer IM. Clinical guidelines for depressive disorders in childhood and adolescence. Eur Child Adolesc Psychiatry. 2000; 9(3):147-161.

15. Fombonne E, Wostear G, Cooper V, Harrington R, Rutter M. The Maudsley long-term follow-up of child and adoelscent depression. I. Psychiatric outcomes in childhood. Br J Psychiatry. 2001;179:210-217.

16. Fombonne E, Wostear G, Cooper V, Harrington R, Rutter M. The Maudsley long-term follow-up of child and adoelscent depression. II. Sucidality, criminality and social dysfunction in adulthood. Br J Psychiatry. 2001;179:218-223.

17. Brennan J. The many faces of depression in children and adolescents. Review of psychiatry. Aust N Z J Psychiatry. 2003;37(5):630-631.

18. Lagges AM, Dunn DW. Depression in children and adolescents. Neurol Clin. 2003;21(4):953-960.

19. Luby JL, Heffelfinger AK, Mrakotsky CM, et al. The clinical picture of depression in preschool children. J Am Acad Chld Adolesc Psychiatry. $2003 ; 42: 340-348$
20. National Institute for Clinical Excellence (NICE). Depression in children and young people: identification and management in primary, community and secondary care. 2005. Available from: http://pdf.giofil. it/circopdf/nr500.pdf

21. Ryan ND. Treatment of depression in children and adolescents. Lancet. 2005;366:933-940.

22. Faravelli C, Guerrini Degl'Innocenti B, Aiazzi L, Incerpi G, Pallanti S. Epidemiology of mood disorders: a community survey in Florence. J Affect Disord. 1990;20(2):135-141.

23. Lewinsohn PM, Hops H, Roberts RE, Seeley JR, Andrews JA. Adolescent psychopathology, Part I: Prevalence and incidence of depression and other DSM-III-R disorders in high school students. J Abnorm Psychol. 1993;102:133-144.

24. Bonati M, Clavenna A. The epidemiology of psychotropic drug use in children and adolescents. Int Rev Psychiatry. 2005;17(3):181-188.

25. Geller B, Fox LW, Clark KA. Rate and predictors of prepubertal bipolarity during follow-up of 6- to 12-year-old depressed children. $J$ Am Acad Child Adolesc Psychiatry. 1994;33:461-468.

26. Lewinsohn PM, Klein DN, Seeley JR. Bipolar disorders in a community sample of older adolescents: prevalence, phenomenology, comorbidity, and course. J Am Acad Child Adolesc Psychiatry. 1995; 34(4):454-463.

27. Lewinshon PM, Klein DN, Seeley JR. Bipolar disorder during adolescence and young adulthood in a community sample. Bipolar Disord. 2000;2(32):281-293.

28. American Academy of Child and Adolescent Psychiatry (AACAP) official action. Practice parameters for the assessment and treatment of children and adolescent with bipolar disorders. J Am Acad Child Adolesc Psychiatry. 1997;36(1):138-157.

29. Geller B, Tillman R. Prepubertal and early adolescent bipolar I disorder: review of diagnostic validation by Robins and Guze criteria. J Clin Psychiatry. 2005;66:21-28.

30. Masi G, Perugi G, Millepiedi S, et al. Developmental differences according to age at onset in juvenile bipolar disorder. $J$ Child Adolesc Psychopharmacol. 2006;16(6):679-685.

31. Andreasen NC, Hoenk PR. The predictive value of adjustment disorders: a follow-up study. Am J Psychiatry. 1982;139:584-590.

32. Fabrega H, Mezzich JE, Mezzich AC. Adjustment disorder as a marginal or transitional illness category in DSM-III. Arch Gen Psychiatry. 1987:44:567-572.

33. Snyder S, Strain JJ, Wolf D. Differentiating major depression from adjustment disorder with depressed mood in the medical setting. Gen Hosp Psychiatry. 1990;12:159-165.

34. Bronisch T. Adjustment reactions: a long-term prospective and retrospective follow-up of former patients in a crisis intervention ward. Acta Psychiatr Scand. 1991;84:86-93.

35. Newcorn JH, Strain J. Adjustment disorder in children and adolescents. J Am Acad Child Adolesc Psychiatry. 1992;31(2):318-327.

36. Jones R, Yates WR, Williams S, Zhou M, Hardman L. Outcome for adjustment disorder with depressed mood: comparison with other mood disorders. J Affect Disord. 1999;55:55-61.

37. Jones R, Yates WR, Zhou MH. Readmission rates for adjustment disorders: comparison with other mood disorders. J Affect Disord. 2002; 7:199-203.

38. Casey P. Adult adjustment disorder: a review of its current diagnostic status. J Psychiatr Pract. 2001;7(1):32-40.

39. Jacobson AM, Goldberg ID, Burns BJ, Hoeper EW, Hankin JR, Hewitt K. Diagnosed mental disorder in children and use of health services in four organized health care settings. Am J Psychiatry. 1980;137: 559-565.

40. Faulstich ME, Moore JR, Carey MP, Ruggiero L, Gresham F. Prevalence of DSM-III conduct and adjustment disorders for adolescent psychiatric inpatients. Adolescence. 1986;21:333-337. 
41. Hillard JR, Slomowitz M, Levi SM. A retrospective study of adolescents' visits to a general hospital psychiatric emergency service. Am J Psychiatry. 1987;144:432-436.

42. Masi G, Perugi G, Toni C, et al. Obsessive-compulsive bipolar comorbidity: focus on children and adolescents. JAffect Disord. 2004;78 (3): 175-183.

43. Andreasen NC, Wasek P. Adjustment disorders in adolescents and adults. Arch Gen Psychiatry. 1980;37:1166-1170.

44. Gur S, Hermesh H, Laufer N, Gogol M, Gross-Isseroff R. Adjustment disorder: a review of diagnostic pitfalls. Isr Med Assoc J. 2005;7: 726-731.

45. Casey P, Maracy M, Kelly BD, et al. Can adjustment disorder and depressive episode be distinguished? Results from ODIN. J Affect Disord. 2006;92:291-297.

46. Takei N, Sugihara J. Diagnostic ambiguity of subthreshold depression: minor depression vs adjustment disorder with depressive mood. Acta Psychiatr Scand. 2006;114:144-147.

47. Kashani JH, Allan WD, Beck NC, Bledsoe Y, Reid JC. Dysthymic disorder in clinically referred preschool children. J Am Acad Child Adolesc Psychiatry. 1997;36:1426-1433.

48. Cantwell DP, Baker L. Stability and natural history of DSM-III childhood diagnoses. J Am Acad Child Adolesc Psychiatry. 1989;28:691-700.

49. Harrington RC. Depressive disorder in children and adolescents. Br J Hosp Med. 1990;43(2):108-112.

50. Emslie GJ, Rush AJ, Weinberg WA, Gullion CM, Rintelmann J, Hughes CW. Recurrence of major depressive disorder in hospitalized children and adolescents. J Am Acad Child Adolesc Psychiatry. 1997;36:785-792.

51. Lewinsohn PM, Seeley JR, Hibbbard J, Rohde P, Sack WH. Cross sectional and prospective relationships between physical morbidity and depression in older adolescents. J Am Acad Child Adolesc Psychiatry. 1996; 35(9):1120-1129.

52. Steingard RJ. The neuroscience of depression in adolescence. J Affect Disord. 2000;61:15-21.

53. Fonagy P. The human genome and the representational world: the role of early mother-infant interaction in creating an interpersonal interpretive mechanism. Bull Menninger Clin. 2001;65:427-428.

54. Lieb R, Isensee B, Hofler M, Wittchen HU. Parental depression and depression in offspring: evidence for familial characteristics and subtypes? J Psychiatr Res. 2002;36:237-246.

55. Nomura Y, Wickramaratne PJ, Warner V, Mufson L, Weissman MM. Family discord, parental depression and psychopatology in offspring: ten-year follow-up. J Am Acad Child Adolesc Psychiatry. 2002;41(4): 402-409
56. Zandio M, Ferrin M, Cuesta MJ. [Neurobiology of depression]. An Sist Sanit Navar. 2002;25(3):43-62.

57. Margari L (a cura di) Estensori: Fabrizi Anna, Masi Gabriele, Presicci Anna et al. Linee Guida diagnostiche terapeutiche gestionali sui disturbi depressivi in età evolutiva. Piccin Nuova Libraria SpA 2008.

58. Boyd ST. Psychological reactions of disaster victims. SAfr Med J. 1981; 60:744-748

59. Saylor CF, Macias M, Wohlfeiler M, Morgan L, Awkerman NG. Exposure to Potentially Traumatic Life Events in Children with Special Needs. Child Psychiatry Hum Dev. 2009;40(3):451-465. www. springerlink.com/content/n2531h1128k08112/fulltext.html

60. Kovacs M, Obrosky DS, Gatsonis C, Richards C. First-episode major depressive and dysthymic disorder in childhood: clinical and sociodemographic factors in recovery. J Am Acad Child Adolesc Psychiatry. 1997; 36:777-784.

61. Akiskal HS. Developmental pathways to bipolarity: are juvenile-onset depressions pre-bipolar? J Am Acad Child Adolesc Psychiatry. 1995; 34:754-763.

62. Carlson GA. The challenge of diagnosing depression in childhood and adolescence. J Affect Disord. 2000;61:3-8.

63. Angst J. The bipolar spectrum. Br J Psychiatry. 2007;190:189-191.

64. Monroe SM. Life events and disorder: event-symptom associations and the course of disorder. J Abnorm Psychol. 1982;91:14-24.

65. Goodyear JM, Kalvin I, Gatzanis S. The impact of recent undesirable life events on psychiatric disorders in childhood and adolescence. Br J Psychiatry. 1987;151:179-184.

66. Brown JD, Siegel JM. Attributions for negative life events and depression: the role of perceived control. J Pers Soc Psychol. 1988;54:316-322.

67. Wagner BM, Compas BE, Howell DC. Daily and major life events: a test of an integrative model of psychosocial stress. Am J Community Psychol. 1988;16:189-205.

68. Woolston JL. Theoretical considerations of the adjustment disorders. J Am Acad Adolesc Psychiatry. 1988;27:280-287.

69. Kety SS, Rosenthal D, Wender PH, Schulsinger F. The types and prevalence of mental illness in the biological and adoptive families of adopted schizophrenics. J Psychiatr Res. 1968;6:345-362.

70. Klerman GL. The spectrum of mania. Compr Psychiatry. 1981;22:11-20.

71. Benazzi F. A continuity between bipolar II disorder and major depressive disorder? Prog Neuropsychopharmacol Biol Psychiatry. 2006; 30:1043-1050.
Neuropsychiatric Disease and Treatment

\section{Publish your work in this journal}

Neuropsychiatric Disease and Treatment is an international, peerreviewed journal of clinical therapeutics and pharmacology focusing on concise rapid reporting of clinical or pre-clinical studies on a range of neuropsychiatric and neurological disorders. This journal is indexed on PubMed Central, the 'PsycINFO' database and CAS, and is the official

\section{Dovepress}

journal of The International Neuropsychiatric Association (INA). The manuscript management system is completely online and includes a very quick and fair peer-review system, which is all easy to use. Visit http://www.dovepress.com/testimonials.php to read real quotes from published authors. 